Check for updates

London, UK

Cite this as: BMJ 2020;371:m4722 http://dx.doi.org/10.1136/bmj.m4722 Published: 08 December 2020

\title{
Microscope detective: consultant histopathologist lan Proctor
}

\section{The consultant histopathologist and training programme director for north and central London speaks to Kathy Oxtoby about what makes his specialty so rewarding}

Kathy Oxtoby

There is something of the detective about Ian Proctor. A consultant histopathologist at University College London Hospital (UCLH), he likens the process of examining tissue under a microscope to investigative work, because it involves "coming up with answers."

"The neck lump you're looking at could be anything from lymphoma or metastatic carcinoma to tuberculosis. It's all down to histopathology," he says. "And the exciting part about my job is that I'm often the first person to identify a diagnosis in a patient. It's important work, and challenging, but histopathology is a bit of an unsung specialty."

Proctor says he likes working in a small specialty because "it makes you feel a bit special. You're in demand."

As training programme director for north and central London and a former lead education supervisor at UCLH, he enjoys sharing his knowledge. His love of training and the opportunity to inspire trainee pathologists stems from the lack of teaching he feels he received as a medical student.

"The way that training for junior doctors was delivered in the 1990 s seemed haphazard. Many of my trainers didn't seem interested in teaching, and I didn't feel particularly inspired by them," he says. "The 'watch one, do one, teach one,' approach suits some people who like shooting from the hip but not me. I'd come from an academic background that was very methodical and demanded a high level of training."

One of the difficulties the specialty faces is that medical students and junior doctors “don't really experience histopathology-some don't even know it exists," says Proctor. "When junior doctors become trainee histopathologists it's often the first time they've looked down a microscope at a piece of tissue. They can find this intimidating, but also exciting," he says.

His interest in looking down a microscope-which he describes as "300 year old technology"-was sparked at school, "although back then I was looking at slides of onion skins."

For Proctor, life outside the laboratory involves spending time with his wife and children, and trips to the cinema. "I'll watch literally anything, from arthouse to action films," he says. "It's all about escapism-I'm an anxious person and I worry about the life changing diagnoses that patients on the end of those slides have received. Cinema is a way of switching off."

In the future, Proctor would love to be dean of a medical school and he's considering training to formally hone his teaching skills. In the meantime, he's been preparing trainees for their final exams, as well as encouraging future generations of potential doctors to consider histopathology as their chosen specialty. He participates in the UCLH summer school for A level students wanting to find out more about a career in medicine, which is also an opportunity to promote the specialty he loves.

"To encourage them to want to know more about histopathology, I like to make things interesting by putting what I do into context," he says. "That a neck lump could be anything, and that it's down to histopathologists to come up with the answers-just like a detective."

\section{Nominated by Sabina Mistry}

Dr Proctor is committed and dedicated to the education of histopathology trainees. He's an excellent and engaging teacher, and I truly believe that he goes above and beyond for the trainees under his care. He actively makes time for every single trainee and listens to them, but also has the unique ability to make them feel valued. Sabina Mistry is a histopathology registrar 